\title{
The first ceratopsian dinosaur from South Korea
}

\author{
Yuong-Nam Lee • Michael J. Ryan • \\ Yoshitsugu Kobayashi
}

Received: 20 July 2010 /Revised: 2 November 2010 / Accepted: 2 November 2010

(C) Springer-Verlag 2010

\begin{abstract}
In 2008, a new basal neoceratopsian was discovered in the Tando beds (Albian) of Tando Basin in South Korea. It represents the first ceratopsian dinosaur in the Korean peninsula and is assigned to Koreaceratops hwaseongensis gen. et sp. nov. Autapomorphies of Koreaceratops include very tall neural spines over five times higher than the associated centra in the distal caudals, and a unique astragalus divided into two fossae by a prominent craniocaudal ridge on the proximal surface. A phylogenetic analysis indicates that Koreaceratops is positioned between Archaeoceratops and all more derived neoceratopsians, and the elongation of caudal neural spines was an important derived character in non-ceratopsid neoceratopsians. The very tall caudal neural spines in Koreaceratops, Montanoceratops, Udanoceratops, Protoceratops, and Bagaceratops appear to be homoplasious, suggesting an independent adaptation, possibly for swimming. Skeletal evidence suggests that obligate quadrupedalism occurred gradually in neoceratopsians progressing from bipedal through facultative quadrupedalism, to complete quadrupedalism in Coronosauria.
\end{abstract}

Communicated by Robert Reisz

Electronic supplementary material The online version of this article (doi:10.1007/s00114-010-0739-y) contains supplementary material, which is available to authorized users.

Y.-N. Lee $(\bowtie)$

Korea Institute of Geoscience and Mineral Resources,

Daejeon, South Korea

e-mail: ylee@kigam.re.kr

\section{J. Ryan}

Cleveland Museum of Natural History,

Cleveland, USA

Y. Kobayashi

Hokkaido University Museum,

Hokkaido, Japan
Keywords Basal neoceratopsian $\cdot$ Koreaceratops hwaseongensis · Tando beds · Late Early Cretaceous . Hwaseong City $\cdot$ South Korea

\section{Introduction}

Ceratopsia (horned-dinosaurs) consists of numerous basal taxa and Ceratopsidae which are most easily recognized by presence of the rostral bone (You and Dodson 2004). While ceratopsids comprise large-bodied, quadrupedal, herbivorous ornithischians typified by elongate postorbital brown horns and expansive shield-like frills that may have elaborate ornamentation, basal ceratopsians are small, bipedal or quadrupedal forms (Dodson et al. 2004). Ceratopsians appear to have originated in Asia with the earliest basal ceratopsian being Yinlong downsi (Xu et al. 2006) from the early Late Jurassic of China. The basalmost neoceratopsians are confined to the Late Jurassic and Early Cretaceous of China, with some psittacosaurids also being known from western Siberia, Mongolia, and possibly Thailand (Sereno 2010). By the Late Cretaceous, basal neoceratopsians became common in North America and more widely distributed in Asia, especially in the Gobi region that has produced nearly all of the Asian genera (Chinnery-Allgeier and Kirkland 2010). Ceratopsids were confined to the Late Cretaceous (Santonian Maastrichtian) of North America until the discovery of a centrosaurine Sinoceratops zhuchengensis from China (Xu et al. 2010). The putative ceratopsid, Turanoceratops, is also known from the Turonian of Uzbekistan (Farke et al. 2009; Ryan 2009; Sues and Averianov 2009a, b).

In 2008, a new basal ceratopsian was discovered in the Tando beds (Lower Cretaceous) of Tando Basin in Korea (Fig. 1). It represents the first ceratopsian dinosaur 


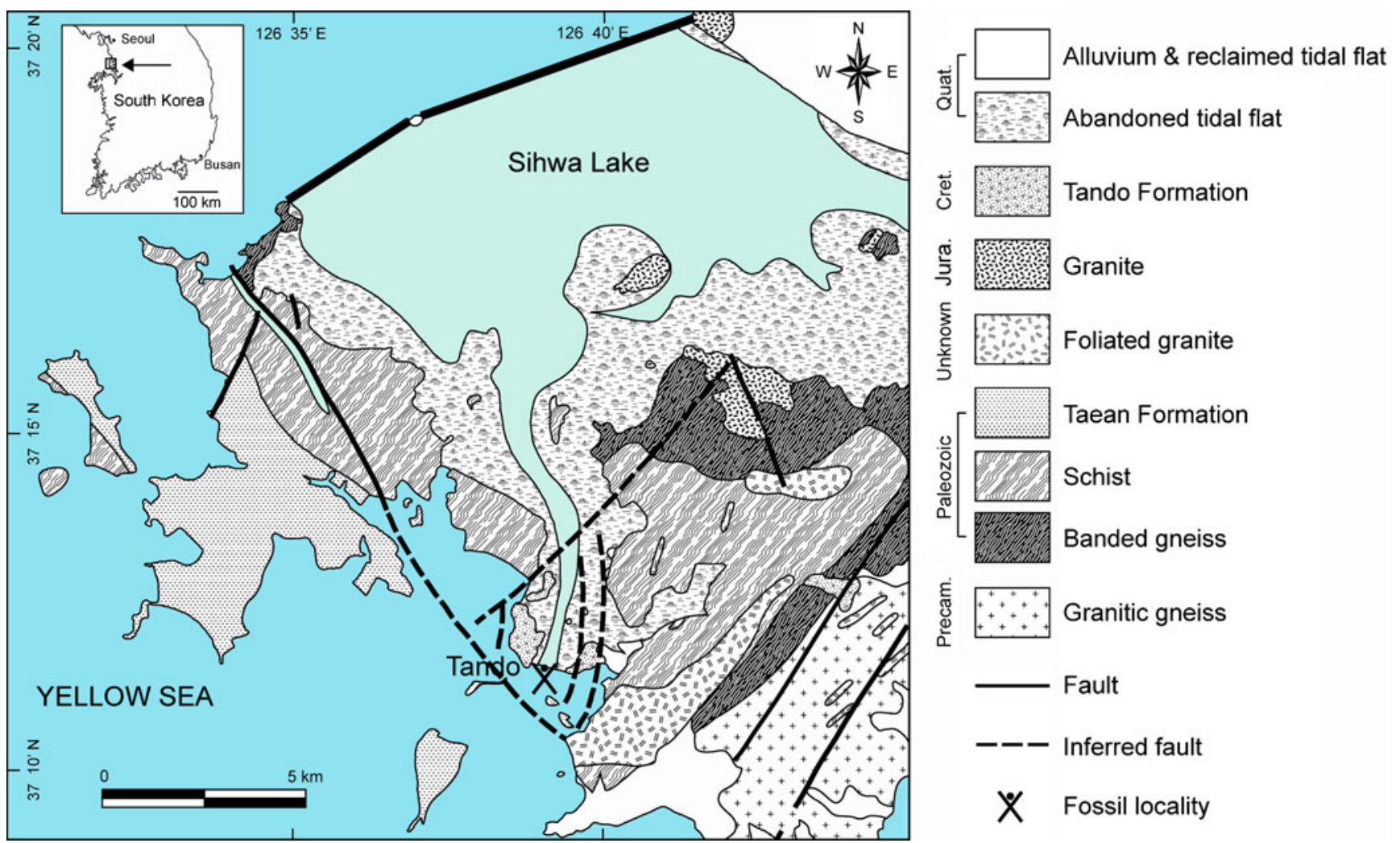

Fig. 1 Regional geologic map in the vicinity of the Tando Basin (modified after Park and Kim 1972; Kim et al. 2009). The Tando beds are uncomfortably underlain by the basement of Precambrian

from the Korean peninsula. This new basal ceratopsian is not only an important contribution to the growing database of basal ceratopsians in Asia, but it is also an important datum for the paleogeographic distribution of this group since it represents the easternmost occurrence of the group in Eurasia (contra Lucas 2006; see Kobayashi 2006). It also comes from a time period (Albian) with a very limited fossil record for basal neoceratopsians. The Korean ceratopsian is of particular interest because it has very long caudal neural spines which are comparable to those of some Late Cretaceous basal ceratopsian taxa such as Protoceratops, Bagaceratops, Udanoceratops, and Montanoceratops. The purpose of this paper is to describe the new basal ceratopsian from the Tando beds, Hwaseong City in Korea and to compare it with other basal ceratopsians to establish its phylogenetic position.

\section{Systematic paleontology}

Dinosauria Owen 1842

Ornithischia Seeley 1888

Ceratopsia Marsh 1890

Neoceratopsia Sereno 1986

Koreaceratops hwaseongensis, gen. et sp. nov. metamorphic and Mesozoic plutonic rocks, deposited mainly in the fault-bounded basin

Etymology The genus and species are named after Korea and Hwaseong City, respectively, which yielded the holotype.

Holotype KIGAM VP (Korea Institute of Geoscience and Mineral Resources, Vertebrate Paleontology, Daejeon) 200801, a nearly complete tail with both ischia, partial distal hind limbs and feet (Figs. 2 and 3).

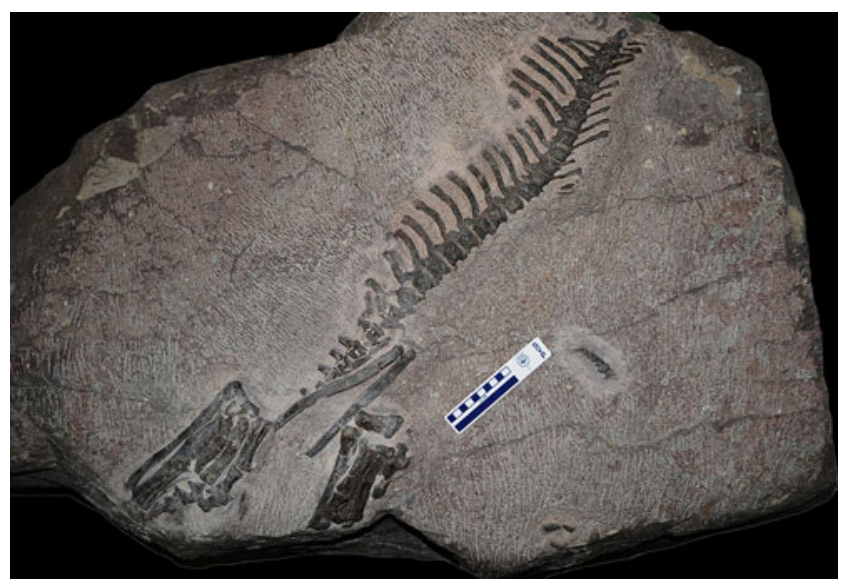

Fig. $2 K$. hwaseongensis, gen. et sp. nov., from the Tando beds (Albian) of Tando Basin in South Korea (KIGAM VP 200801, holotype) in ventral view. The proximal tibiae and fibulae are sharply cut off at the edge of the block 


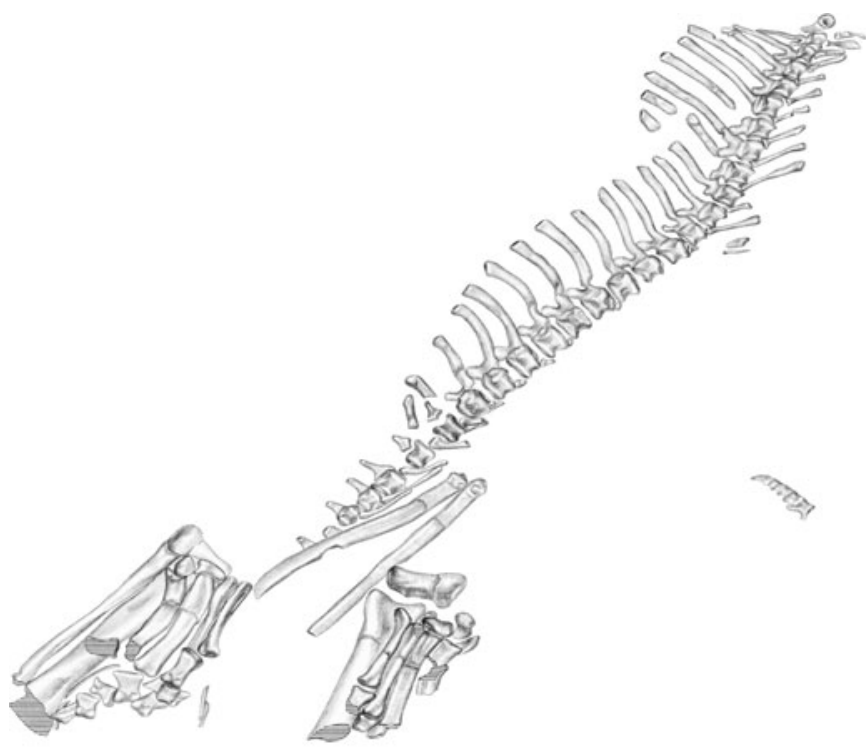

Fig. 3 Illustrations of $K$. hwaseongensis, gen. et sp. nov., with anatomical abbreviations: ast astragalus, $c a$ calcaneum, $c v$ caudal vertebra, $F i$ fibula, isc ischium, $m t$ metatarsal, $n s$ neural spine, $p r$

Type locality and geological setting The Tando Basin is a very small basin (approximately $25 \mathrm{~km}^{2}$ ) located in midwest Korea (Fig. 1). This terrestrial Cretaceous sedimentary basin was found in 1972 (Park and Kim 1972) and officially named as the Tando Basin by Park et al. (2000). The basin is mainly filled with clastic sediments, which consists of predominantly purple, fine-grained sandstones and siltstones, and thin sandstones with thick conglomeratic sandstones in the lower part, and well-bedded tuffaceous rocks and cherty mudstones in the upper part. Although we regard these deposits as deserving of formational status, they are referred to here as the Tando beds, pending a full description and establishment of a type section. The Tando beds crop out on several small islands in the basin such as Tando, Buldo, Ttakseum, Goryeom, and Seoksan islands.

KIGAM VP 200801 was found in a block of rock in the rock-filled Tando embankment dam between the Tando dock and the Jeongok harbor by a public official of Hwaseong City in 2008. The block $(80 \mathrm{~cm} \times 60 \mathrm{~cm} \times$ $80 \mathrm{~cm}$ ) containing the bones is composed of reddish, finegrained sandstone (Fig. 2). The Tando embankment dam was built in 1994 with rocks taken both from the Tando and Buldo quarries. Based on the lithology of rocks from these abandoned quarries, it is believed that the source rock of the block containing the specimen was originally from the lower part of the Tando beds. Six ornithopod tracks were previously reported from the tuffaceous sandstone and cherty mudstone in the upper layers of the Tando beds (Choe et al. 2001). Fossil palynomorphs for age determination could not be acquired because of the oxidation and

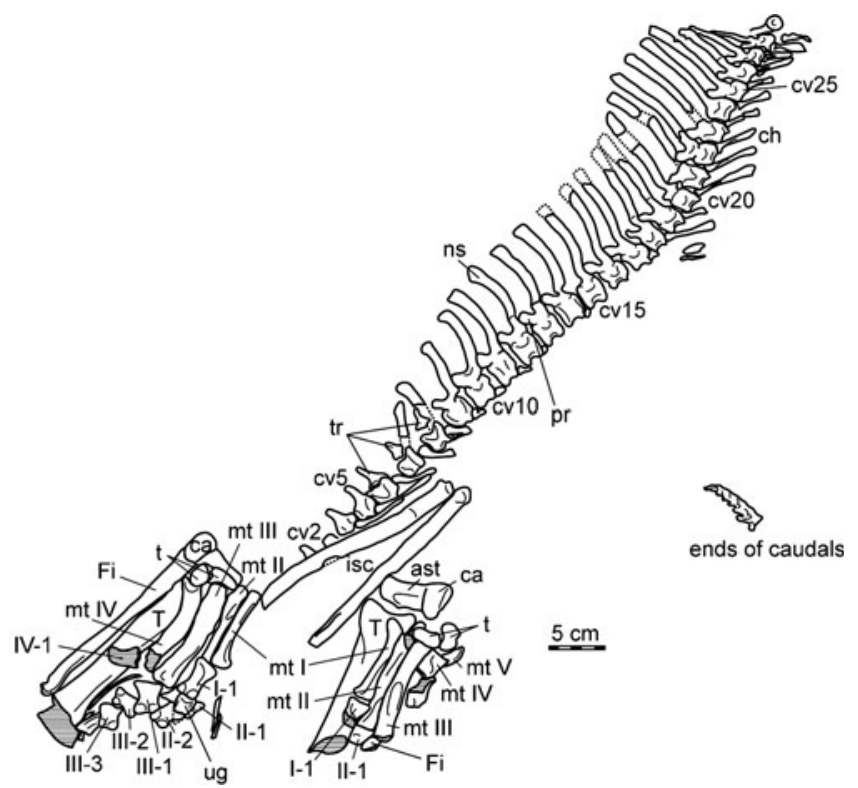

prezygapophysis, $T$ tibia, $t$ tarsal, $t r$ transverse process, $u g$ ungual. Cross-hatch pattern indicates broken edge of bone and partial restorations of neural spines are shown with dotted lines

thermal alternation of the sediments by volcanic activities in this area (Yi et al. 2004). $\mathrm{K}-\mathrm{Ar}$ plagioclase and biotite age of three andesitic tuff samples from the upper section of the Tando beds is $103 \pm 0.5 \mathrm{Ma}$ indicating that the Tando beds are late Early Cretaceous in age (Albian).

Diagnosis Very tall neural spines over five times higher than the associated centra in the distal portion of the caudal vertebrae except for caudalmost caudals; surface of astragalus capping the distal end of the tibia divided into two fossae by a prominent craniocaudal ridge; triangular-shaped calcaneum is 1.5 times longer craniocaudally than the astragalus in proximal view.

Description KIGAM VP 200801 consists of the nearly articulated, partial hind limbs and tail of a small basal neoceratopsian. The proximal tibiae and fibulae are sharply cut off at the edge of the block (Fig. 2), suggesting that the rest of the skeleton could have been present before the block was broken up in the quarry, but this cannot now be determined. Preserved elements are the caudal vertebrae, ischia, tibiae, fibulae, tarsals, metatarsals, and phalanges (Fig. 3) and the measurements of each bone are given in Online Resource 1 .

The specimen preserves a nearly complete tail of 36 vertebrae. Possibly four or five vertebrae are missing from the posterior end of the caudal series, but the delicate terminal distal caudals are preserved detached from the rest of the tail. The estimated length of the tail is approximately $813 \mathrm{~mm}$. The articular surfaces of the centra of the caudal vertebrae are sub-rounded, decreasing in all dimensions caudally. They are spool-shaped in lateral view and tightly 
articulated to each other except for the detached distal end. Each centrum of the main portion of the tail has two welldeveloped chevron facets on the caudoventral margin, and a slight depression on the cranial surface of the centrum. The caudalmost seven preserved caudal centra are completely fused to one another, elongate, and lack neural spines and chevrons. Transverse processes decrease in size caudally and persist until caudal 11. In dorsal view, each transverse process is triangular in shape with a broad, convex base along the centroneurapophysial suture. The proximal eight transverse processes are not fused with the centrum. The length of the best preserved transverse process from caudal 5 is $23.0 \mathrm{~mm}$. The neural spines on the first eight caudals are incomplete or broken. In general, the neural spines are very tall and slightly inclined caudally, and concave cranially in lateral view. Their cross-sections are subrectangular and they are very flat laterally. The neural spines from caudal 9 to caudal 14 are well preserved and slightly flared craniocaudally at the distal end. The neural spines of these caudals increase caudally from 52.4 to $85.8 \mathrm{~mm}$ in length. The total height of caudal 14 , including the neural spine, is $128.2 \mathrm{~mm}$. The distal ends of the neural spines beyond that point are broken until caudal 20 in which the neural spine is $97.3 \mathrm{~mm}$ in length. The lengths of the spines increase continuously to caudal 22 , where the spine reaches the maximum length of $98.9 \mathrm{~mm}$ (measured from a point above its base) with a total height of $134.5 \mathrm{~mm}$. This neural spine is approximately 5.6 times as high as the vertebral centrum. From this point, the lengths of neural the spines decrease abruptly to caudal 28 . Therefore, the tallest neural spines occur in the distal tail rather than in the middle. The tip of the tail (last seven caudals) lacks neural spines. Neural arch bases and articular processes are evident as far caudally as the tip of the tail except for last six caudals. Pre- and postzygapophyses form lobe-like projections craniodorsally and caudodorsally with approximately equal height, respectively. Prezygapophyses are slightly larger and longer than the post-zygapophyses. The latter are more inclined to the dorsal than the former, which are inclined at approximately $60^{\circ}$ to the horizontal. The prezygapophyses project beyond the cranial margin of the centrum and articulate laterally with the post-zygapophyses of the preceding caudal. Preserved chevrons persist until caudal 28, but almost half of these are missing or incomplete. All chevrons are oriented caudoventrally and intersect the axis of the tail at a $45^{\circ}$ angle. Well-preserved chevrons are rod-like and straight in lateral view. In cranial and caudal view, they are triangular in shape with a triangular foramen for the hemal artery. The articular surface of the hemal arches becomes progressively smaller along the caudal series while the distal portion becomes slightly expanded craniocaudally and flattened laterally. Chevrons are consistent in length until caudal 22, but rapidly shorten beyond this point.
Both ischial shafts are preserved, although lacking proximal ends. Each shaft is $195 \mathrm{~mm}$ long, as preserved, and narrow and sub-oval in cross-section. Although they diverge from the midline proximally, each shaft is essentially straight, contacting with each other along their distal surfaces. The distal ends of both shafts are swollen, with a rugose surface.

Unfortunately, the proximal ends of both lower hind limbs are not preserved so their exact lengths cannot be determined. The shaft of the tibia is cylindrical and the distal end flares mediolaterally. The width of the distal end is $61 \mathrm{~mm}$ and its craniocaudal length is $17 \mathrm{~mm}$. The fibular, calcanear, and astragalar articulations are distinct. The inner malleolus is wide and flared to articulate with the concave surface of the astragalus. The outer malleolus bears a narrow cranial flange forming part of the articular surface for the distal end of the fibula. Thus, the astragalar facet is both higher and wider than the calcanear facet. The distal surface of the tibia between the two malleoli is concave and receives the prominent craniocaudal ridge on the inner surface of the astragalus. The distal end of tibia must be rotated relative to the proximal end, but the extent of this cannot be determined. The preserved left and right tibiae are 222 and $152 \mathrm{~mm}$ long, respectively.

As for all ceratopsians, the fibula is much more gracile than the tibia. The proximal portion is slightly curved and concave on the medial surface, but the midshaft is oval in cross-section. Below the midshaft, a raised edge is developed craniolaterally. The distal end of the fibula is positioned directly dorsal to the calcaneum. The anterior surface of this distal end is slightly concave dorsoventrally while the posterior surface against the tibia is flat. The ventral portion of the distal end is convex to fit into the triangular fossa of the calcaneum (Fig. 4c).

The astragali and calcanei are perfectly preserved in both feet (Fig. 4). The astragalus is tightly fused to the calcaneum laterally. The astragalus consists of a rhomboidal body and an ascending process overlapping the cranial surface of the tibia. The astragalar body is slightly constricted in the middle, forming a smooth, cylindrical surface for the intertarsal articulation distally. It bears lateral and medial expansions. Both expansions are hemispherical in shape, and the medial expansion is thicker than its shallow lateral counterpart, forming a wedge in caudal view. In proximal view a prominent craniocaudal ridge divides the astragalus into a larger medial, and smaller lateral, fossae into which the inner and outer malleoli of the tibia insert, respectively. The outer malleolus of the tibia also extends onto the caudolateral margin of the calcaneum. The astragalus measures $37.5 \mathrm{~mm}$ in width, $65 \%$ of the width of the distal tibia. The cranial ascending process is wide, low, and bluntly squared off proximally. In cranial view, the height of the ascending process is less than the height of the calcaneum. It does not completely cover the inner malleolus of the tibia, so that the tibia is widely exposed craniomedially where the 

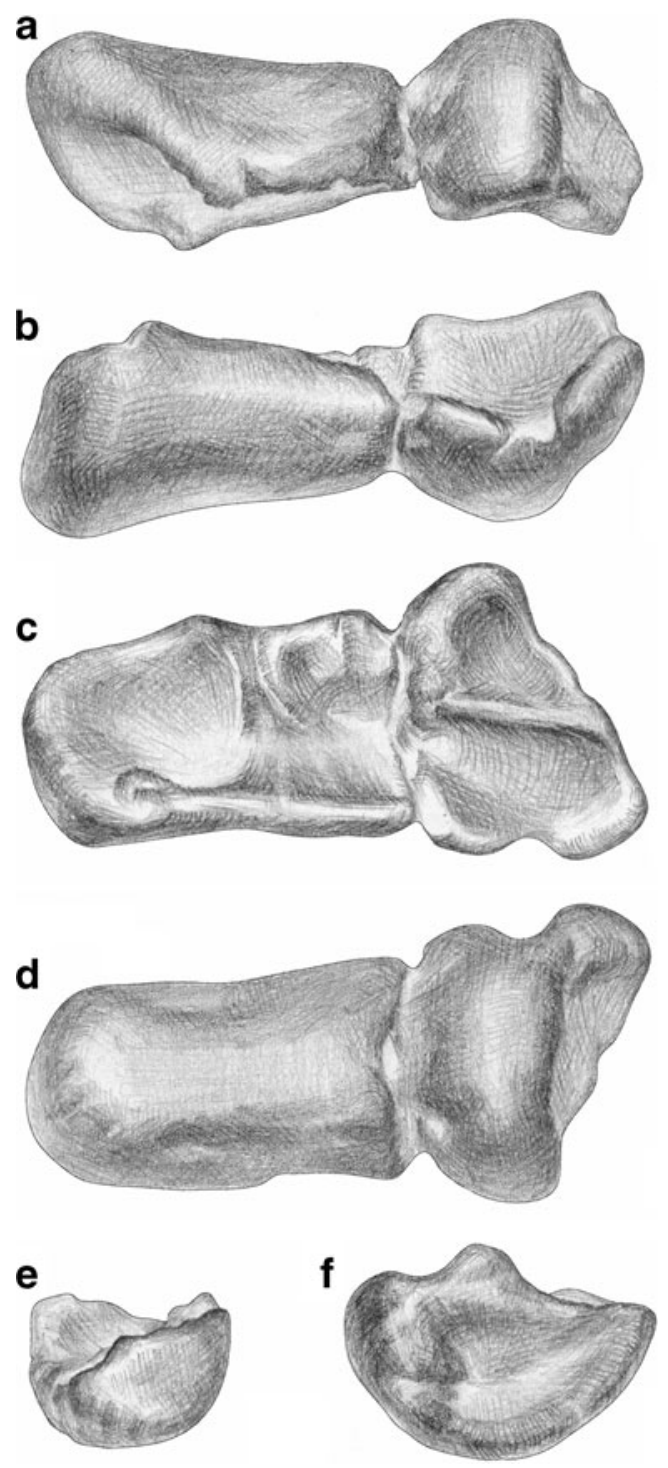

Fig. 4 Left astragalus and calcaneum of $K$. hwaseongensis, gen. et sp. nov. a cranial view; b distal view; c proximal view; d ventral view; e medial view; f lateral view

process is indented proximal to the astragalus body. A broad and shallow depression is developed at the junction of the body and ascending process making the cranial surface of astragalus flatter than the caudal surface.

The calcaneum is firmly fused to the astragalus medially. It is distinctively expanded proximodistally and craniocaudally, making a larger body configuration than the astragalus. In proximal view, it is triangular in shape with two fossae which are completely separated by a sharp ridge. The larger caudal fossa provides a broad and shallow surface for stabilizing the strongly developed outer malleolus of the tibia. This fossa is also open caudally, but its cranial surface is nearly vertical and has a sharp ridge to firmly contact the tibial facet. The upper, smaller fossa of the calcaneum provides a concavity for the distal end of the fibula. The cranial portion of this fossa is thickened to support the downward force of the fibula. In distal view, the calcaneum contacts the astragalar body by a trochleated joint, but the constriction along astragalocalcaneal suture is strong and offset above the level of the astragalus. In lateral view, the calcaneum is semicircular, with a convex distal outline and two concave proximal margins. Its diameter is $32.5 \mathrm{~mm}$, exceeding the medial diameter of the astragalus $(23.0 \mathrm{~mm})$.

Two distal tarsals are preserved in both feet. The medial and lateral tarsals contact the proximal end of metatarsals III and IV, respectively. The medial tarsal is flat and larger (24 mm, left foot; $27 \mathrm{~mm}$, right foot) than the lateral (16 and $17 \mathrm{~mm}$, respectively). The proximal end of the medial tarsal is sub-rounded mediolaterally while the lateral is oval in shape. Each tarsal is assumed to be in situ since they occur in the same position on both feet.

The elongate and slender metatarsals of both feet are preserved, exposing the plantar surfaces. The left metatarsals are complete except for the damaged distal end of $\mathrm{mt}$ IV. Metatarsals I and II are complete in the right foot, but the distal end of $\mathrm{mt}$ III is broken and only the proximal portion is preserved for mt IV. A small flat splint is attached to the proximal end of $\mathrm{mt}$ IV laterally, representing $\mathrm{mt} \mathrm{V}$. Among the four functional metatarsals, $\mathrm{mt}$ III is the longest and stoutest with the shortest being $\mathrm{mt}$ I. Metatarsal I measures $73.2 \mathrm{~mm}$ in length, $68 \%$ of the length of $\mathrm{mt}$ III $(107.8 \mathrm{~mm})$ in the left foot. The relative length between $\mathrm{mt}$ II and $\mathrm{mt}$ IV is not certain because $\mathrm{mt}$ IV are incomplete in both feet. The proximal end of $\mathrm{mt} \mathrm{I}$ is expanded craniomedially and convex proximally. Its lateral surface is also convex, while the medial surface is flat. The distal end is subtriangular in cross-section with two well-formed distal articular condyles, of which the lateral is more prominent than the medial. The shaft is thin and compressed mediolaterally between both expanded ends. The completely exposed $\mathrm{mt}$ II is $97.6 \mathrm{~mm}$ long in the right foot, which is $10 \mathrm{~mm}$ shorter than the $\mathrm{mt}$ III in the left foot. In proximal view, the proximal end is elongate craniocaudally. In caudal view, it is convex proximally, and its lateral surface is slightly convex while the medial surface is slightly concave to fit against the lateral surface of $\mathrm{mt} \mathrm{I}$. The shaft is compressed mediolaterally. The distal surface is a crescentic in cross-section with two condyles, of which the lateral is slightly more developed than the medial. Metatarsal III is slightly curved laterally from the mid shaft. The proximal end is wide and rectangular in cross-section, and contoured to fit against distal tarsal 1. Its medial surface is slightly concave to fit into the lateral surface of $\mathrm{mt}$ II, while the lateral is convex. The shaft is not compressed, remaining wide until the distal end, which is subrectrangular in cross-section with two moderately sized condyles that are almost symmetrical in distal view. The distal half of mt IV diverges laterally. Its proximal end is 
concave in proximal view which fits into a rounded tarsal 2 . The shaft is somewhat triangular in outline with a sharp lateral margin formed by the junction of the gently convex cranial and concave caudal surfaces. Metatarsal V is reduced to a splint which is preserved in the right foot. It is a flat triangular bone in lateral view. Its proximal end is craniocaudally expanded and articulated with the craniolateral surface of $\mathrm{mt}$ IV.

A total of ten phalanges are preserved including one ungual. In the right foot, a phalange is articulated with the distal end of $\mathrm{mt} \mathrm{I}$ and $\mathrm{mt}$ II, respectively, but only a proximal portion is preserved in both. In the left foot, eight phalanges are preserved, but most distal phalanx is missing. Therefore, it is not possible to determine the exact phalangeal formula, except for digit I. The phalanges are slightly displaced, but their positions can be determined based on their relative size and morphologies (Fig. 3). Although the relative length and width of these phalanges varies, their general morphology (except for the unguals) is very similar to each other. In ventral view, the proximal ends of the first phalanges of each digit are somewhat slightly concave, but they are convex in the more distal phalanges. Two distal condylar heads are well developed on each phalange. The ungual of digit I from the left foot is slender and pointed, with the grooves for the claw along the lateral margins.

\section{Phylogenetic analysis}

$K$. hwaseongensis is a new basal neoceratopsian taxon. The currently known hypodigm for Koreaceratops can only be coded for 6 out of 133 characters listed in the charactertaxon matrix for Ceratopsia compiled by Makovicky and Norell (2006) and Makovicky (2010) because only partial postcranial elements without a cranium are available for the specimen. The coded characters for Koreaceratops are 116 (1), $117(0), 118(1), 129(0), 132(0)$, and 133 (0). From the detailed observation on Koreaceratops, three new characters were added to the matrix: the height ratio of middle caudal neural spine to associated centrum (char. 134), less than or equal to 2 (0), 2.1 3 (1), 3.1 4 (2), more than 4.1 (3); the width of proximal end of the ungual relative to width of distal end of the preceding phalanx (char. 135), equal (0), wider (1); the height of the caudal neural spine is greater than the length of the chevron for any given caudal vertebra (char. 136), absent (0), present (1). To determine the phylogenetic position of $K$. hwaseongensis, a cladistic analysis was conducted using PAUP*, $4.0 \mathrm{~b} 10$ (Swofford 1998). The branch-and-bound parsimony algorithm in PAUP* was performed for 21 taxa including two outgroups with equally weighted and unordered 136 characters as shown in Online Resource 2. Asiaceratops (Nessov et al. 1989) was not included in this analysis due to its questionable taxonomic status (but see Averianov and Sues 2009). The analysis resulted in four most parsimonious trees. The only difference between these four trees is the internal topologies of Udanoceratops, Leptoceratops, Udanoceratops, and Prenoceratops. Strict consensus methods were used to analyze the commonality of branching patterns between these four trees. This strict consensus tree has a length of 241 steps, a consistency index of 0.672 , a rescaled consistency index of 0.527, and a retention index of 0.785 (Fig. 5).
Fig. 5 Strict consensus of four most parsimonious trees resulting from analysis of the 136 characters, 21 taxa matrix $(\mathrm{TL}=241, \mathrm{CI}=0.672$, $\mathrm{RC}=0.527, \mathrm{RC}=0.785$ ) Numbers next to nodes indicate synapomorphies

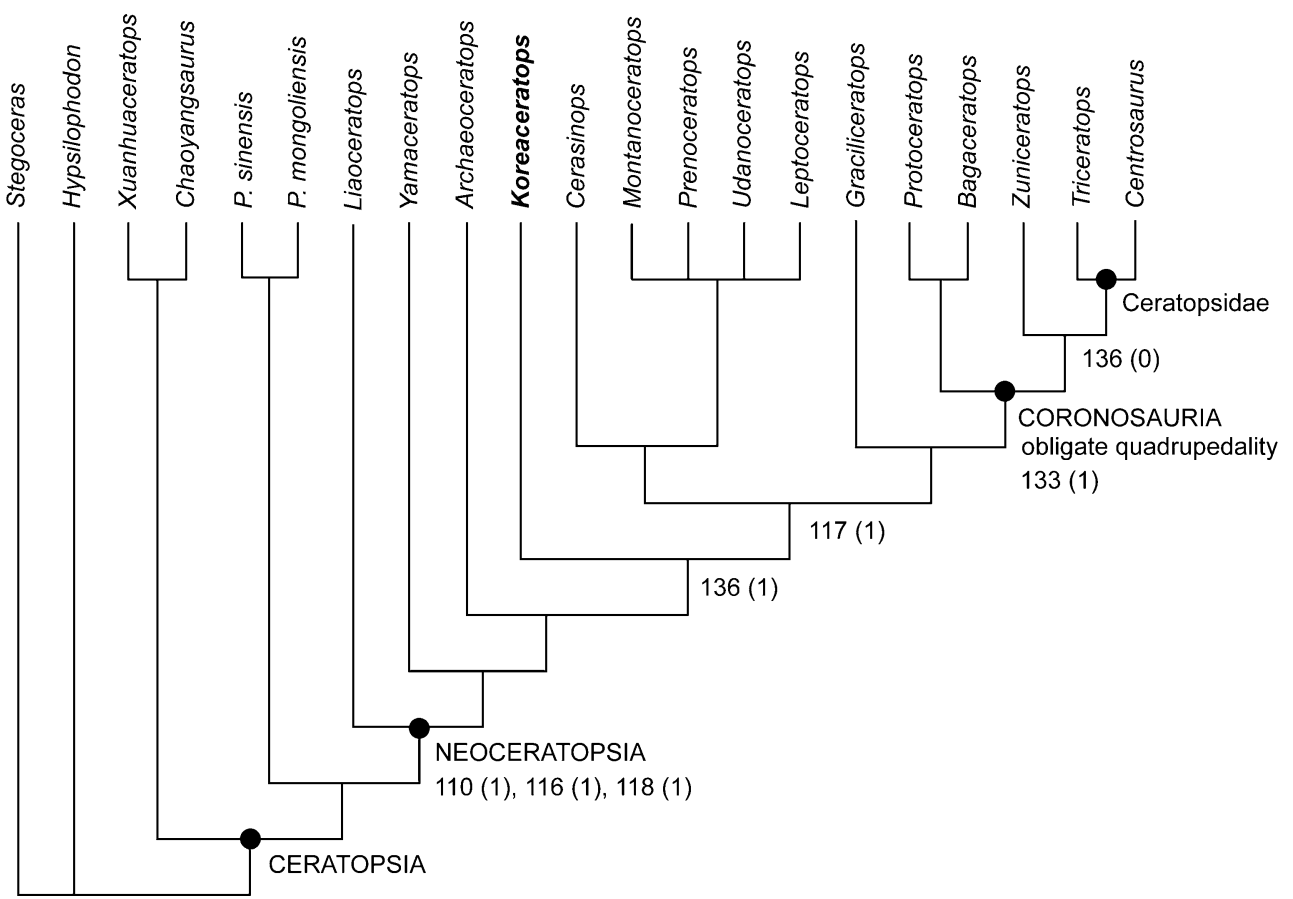


In this analysis, Koreaceratops occupies a phylogenetic position as a basal neoceratopsian intermediate between Archaeoceratops (Dong and Azuma 1997; You and Dodson 2003) and Cerasinops (Chinnery and Horner 2007)+more derived ceratopsians. Liaoceratops, Yamaceratops, Archaeoceratops, and Koreaceratops are successive outgroups to Cerasinops + more derived ceratopsians. Only one unambiguous synapomorphy (char. 136) unites Koreaceratops with higher neoceratopsians, but it is secondarily lost in the Ceratopsoidea (Zuniceratops +Ceratopsidae, sensu Sereno 2000). One unambiguous synapomorphy of the clade comprising Cerasinops and the Leptoceratopsidae (sensu stricto, Makovicky 2001), Graciliceratops and more derived neoceratopsians, but not in Koreaceratops, is that neural spines and chevrons persist virtually to the end of tail (char. 117; note that the end of tail is not preserved in Cerasinops). This character was also recognized by Sereno (2000), but its function in neoceratopsians is not known.

\section{Discussion}

Synapomorphies of Ceratopsia are mainly recognized from cranial elements which include the presence of the rostral, broad pointed jugals, vaulted premaxillary palate, and broad base of the ventral process of the predentary supporting the dentary symphysis (Sereno 2000). Few, if any postcranial synapomorphies have been identified. Although cranial synapomorphies cannot be determined for KIGAM VP 200801, the referral of this specimen to a neoceratopsian can be made by comparison of its preserved skeletal elements to other members of this clade that excludes it from being a more derived ceratopsid, or any other member of Ceratopsia, including Psittacosauridae. The foot of Koreaceratops is gracile and long, having constricted metatarsus and elongate phalanges. It is different from ceratopsid foot which is short and uncompressed, all phalanges wider than long (char. 132, a synapomorphy of the Ceratopsidae). Koreaceratops is not a psittacosaurid because the chevrons of the latter are always longer than the respective neural spines (You and Dodson 2004).

Koreaceratops is a new basal neoceratopsian and it is the first to be recovered from Korea. It represents the easternmost occurrence of this clade in Eurasia and is the oldest neoceratopsian expressing the deep tail profile, predating Udanoceratops by approximately $20 \mathrm{Ma}$. With the late Albian age, it helps to fill in a time gap (Late Albian to Early Santonian) in which few ceratopsian fossils are known (notably the basal neoceratopsian Asiaceratops from the Cenomanian of Uzbekistan (Averianov and Sues 2009; Nessov et al. 1989), and the putative ceratopsid Turanoceratops (Farke et al. 2009; Nessov et al. 1989; Sues and Averianov 2009a, b) from Uzbekistan).
Koreaceratops is diagnosed based on two autapomorphies, the shape of the astragalus and the very tall caudal neural spines. Although similar spines are known for four other basal neoceratopsians (Bagaceratops, Montanoceratops, Protoceratops, and Udanoceratops), none have the combination of length and caudal position seen in Koreaceratops. Montanoceratops from the early Maastrichtian of Montana (Sternberg 1951) and Alberta (Ryan and Currie 1998) has a complete tail which is leaf-shaped. Its tallest neural spine (caudal 15) occurs in the middle of the tail, unlike the more distal position in Koreaceratops, and is only approximately four times as high as its vertebral centrum. Additionally, the lateral portion of the astragalus of Montanoceratops is expanded proximally (Chinnery and Weishampel 1998), a feature not shared with Koreaceratops.

Udanoceratops tschizhovi from the Djadokhta Formation, Mongolia (Kurzanov 1992) also has long neural spines in the middle caudals, but these are only three times as long as the vertebral centrum and therefore shorter than the longer, more distally placed spines of Koreaceratops. The unguals of Udanoceratops are flat and wide, forming an "ungulohoof shape" (sensu Tereschenko 2008, Fig. 5c), and thus differs from the slender and pointed ungual of Koreaceratops.

Protoceratops andrewsi is known from multiple specimens including hatchlings to large adults (Brown and Schlaikjer 1940; Gregory and Mook 1925). The second species, Protoceratops hellenikorhinus, from the Bayan Mandahu Formation, China was described on the basis of a skull discovered by the Sino-Belgian Expeditions (Lambert et al. 2001). The circular or laterally flattened neural spines of the middle caudal vertebrae of Protoceratops are four times as long as their centra, and the unguals are short, wide, and hoof-shaped, again differing from those of Koreaceratops.

Bagaceratops rozhdestvenskyi (Maryańska and Osmólska 1975) from the Baruungoyot Formation (Campanian), Mongolia is very similar to Protoceratops in many details with its most distinctive character being the extremely high caudal neural spines which are five times as high as the vertebral centrum. This ratio of neural spines to the centrum is very similar to that seen in Koreaceratops, however, the foot of Bagaceratops differs from that of Koreaceratops in being relatively short and wide with hoof-shaped unguals.

\section{Evolutionary trends in Ceratopsia}

Even though Koreaceratops lacks the skull it can still help provide important insights into the evolutionary sequence of neoceratopsian postcranial features. Although postcranial shape differences between Psittacosaurus, basal neoceratopsians, and ceratopsids have been recognized by mor- 
phometric analysis (Chinnery 2004), evolutionary trends within the postcranial skeleton of basal neoceratopsians have yet to be described in detail. The addition of Koreaceratops and three newly recognized postcranial characters to the cladistic matrix developed in Makovicky and Norell (2006) and Makovicky (2010) has allowed us to analyze a total of 30 basal neoceratopsian postcranial characters using PAUP*.

Ceratopsoidea is united by 13 synapomorphies (char. 107 (atlas intercentrum semicircular disk shaped), 110 (axial neural spine elongate and posteriorly inclined), 112 (syncervical completely coossified), 115 (outline of sacrum oval in dorsal view), 119 (clavicles present), 123 (olecranon process enlarged), 124 (less than two distal carpals), 125 (manus much closer to pes in size), 127 (postpubis short and posteriorly directed), 128 (prepubis long and flared at anterior end), 129 (ischial shaft straight posterodorsally convex), 131 (tibiofemoral ratio less than one), and 132 (foot short and uncompressed)). Most of these synapomorphies are probably closely related to a shift to larger body sizes in ceratopsids, with a proportionate increase in skeletal robustness and the requirement for the skeleton to support more weight in these derived ceratopsians; these preliminary findings could be more fully resolved with more complete material of Zuniceratops (Wolfe and Kirkland, 1998; Wolfe et al. 2010) which can presently only be scored for character 126 .

Three unambiguous postcranial synapomorphies (char. 110 (axial neural spine tall and hatchet-shaped), 116 (caudal neural spines tall and straight), and 118 (distal chevrons rod-like)) diagnose Neoceratopsia. In more derived taxa both the axial and caudal neural spines become taller, and the distal chevrons become reduced and rod-like. One unambiguous postcranial synapomorphy (char. 136) uniting Koreaceratops with higher neoceratopsians is the caudal neural spines that are much longer than the chevrons. This feature is further exaggerated in some neoceratopsians such as Koreaceratops, Montanoceratops, Udanoceratops, Protoceratops, and Bagaceratops that display height ratios of the middle neural spine to the caudal centrum (char. 134) of $3,2,1,2$, and 3 , respectively. This feature becomes lost secondarily in Ceratopsidae, suggesting that elongation of caudal neural spines may have evolved as a functionally integrated module in non-ceratopsid neoceratopsians more derived than Archaeoceratops.

Koreaceratops is notable for having a claw-like ungual, a character it shares with Cerasinops and Graciliceratops. Sereno (2000) included Graciliceratops in Coronosauria, but Makovicky (2002) regarded it as a metaspecies, although he did note that it retains claw-like pedal unguals, unlike any other coronosaur (Makovicky and Norell 2006). In the most parsimonious trees of this cladistic analysis (Fig. 5), rounded, hoof-like pedal unguals (char. 133) are an unambiguous postcranial synapomorphy of Coronosauria. Increasing size and body weight with a proportional shortening of the tail and limbs occurred in the evolution of ceratopsian dinosaurs. Consequently, this trend was also accompanied by the transition of foot morphology from gracile to robust form. Metatarsals became relatively shorter and wider than seen in more basal forms, while phalanges, including unguals, also became shorter and thicker. The width of the proximal end of the ungual relative to preceding phalanx became larger (char. 135) in Udanoceratops, Graciliceratops, and Coronosauria. Tereschenko (2008) divided ungual shapes into claw-shape, ungulohoof-shape, and hoof-shape based on the ratio of length of ungual to width of its proximal end, with the hoof-shaped unguals typical of Protoceratops, Bagaceratops, and Ceratopsidae being a synapomorphy of Coronosauria. These hoof-shaped unguals are short, wide, flat, and slightly pointed, and have a ratio of length to width that is less than 1.5. Narrow and long claw-shaped unguals are present in non-coronosaurian basal ceratopsians and have ratios of length to width of usually more than 2.0. The "ungulohoof-shaped" ungual of Udanoceratops is intermediate in form being long, flat, and slightly pointed, with ratios of length to width of between 1.5 and 2.0.

Although there is a consensus that ceratopsids were a habitual quadrupeds (Dodson et al. 2004), terrestrial locomotion of non-ceratopsid neoceratopsians is still being debated by researchers (Dodson and Farlow 1997; Paul and Christiansen 2000; Rega et al. 2010; Thompson and Holmes 2007). Coombs (1978) first mentioned that Leptoceratops and Protoceratops were at least facultative quadrupeds based on their forelimb and hind limb proportions. This argument was supported by Senter (2007) with a study of the forelimb morphology and range of motion, but Tereschenko (2008) believed that they were obligate quadrupeds. Senter (2007) pointed out the differences in palm orientation between Leptoceratops and Protoceratops and related these to modes of locomotion. In Protoceratops the palms face posteriorly for typical quadrupedal locomotion, while the fingers of the medially faced palms of Leptoceratops would need to be reoriented for walking. In addition, the trunk of Protoceratops is relatively longer than Leptoceratops, suggesting that the former had a body plan more suitable than the latter for quadrupedal locomotion (Galton 1970; Senter 2007). The development of hoofshaped unguals, typical of many large extant herbivorous quadrupeds and a synapomorphy of Coronosauria, also seems to be in accord with acquisition of quadrupdalism in Coronosauria.

The ratio of the skull and hind limb + foot length of ceratopsian dinosaurs seems to be related to their mode of locomotion, and implies that the development of large skulls may have, in part, required a shift to a quadrupedal 
lifestyle in the most derived ceratopsians. The ratio in Coronosauria is more than 0.7 , while the less-derived Psittacosaurus (recognized as being bipedal) and Cerasinops have ratios of less than 0.4. The ratios for Montanoceratops, Prenoceratops, and Leptoceratops range from 0.60 to 0.65 , indicating that these ceratopsians are intermediate between the former two groups. Based on its phylogenetic position, we predict that when more complete specimens of Koreaceratops are discovered they will have skull-hind limb + foot ratios indicative of a bipedal lifestyle.

This analysis implies that obligate quadrupedalism occurred gradually in neoceratopsians developing from bipedal (probably both Koreaceratops and Cerasinops) to facultative quadrupedal (Graciliceratops, Leptoceratopsidae, sensu stricto Makovicky 2001), and finally to fully quadrupedal (Coronosauria) forms through a progressive increase of body and skull size with a relative elongation in trunk length, and an increase in robustness of the hands and feet with the modification of claws into hoof-shaped unguals.

\section{Behavioral inferences}

The function of long caudal neural spines of Protoceratops has been speculated as being an adaptation for swimming by various authors. Gregory and Mook (1925) suggested that the taxon was aquatic because of its large feet and deep tail. Brown and Schlaikjer (1940) and Barsbold (1974) accepted this idea and suggested that Protoceratops was probably amphibious and a relatively good swimmer based on its laterally flattened tail with very high neural spines. Bailey (1997) disagreed and suggested that the high caudal neural spines were related to a desert mode of life to store fat and metabolic water on the side of tail. Based on paleoecology of Protoceratops from the Djadokhta Formation (e.g., association with ponds or lakes, Eberth 1993), and distinctive anatomical features of its tail (e.g., heterocoelous caudal vertebrae), Tereschenko (2008) concluded that tail height is an indicator of adaptation of "protoceratopoids" for swimming. He argued that Bagaceratops was probably the most aquatic, followed in decreasing swimming ability by Protoceratops, and Udanoceratops, with Leptoceratops being the most terrestrially adapted. If one accepts this argument, then the tall caudal neural spines of Koreaceratops suggests that it could have been a good swimmer.

Such conclusions are difficult to prove, however, given that, unlike psittacosaurs which lack deep tails but are frequently associated with lacustrine deposits, and have long been suggested to have had an aquatic component to their behavior (e.g., Ford and Martin 2010, Rozhdestvensky 1955; Suslov 1983), many deep-tailed Protoceratops specimens have been recovered from eolian deposits. Additionally, other deep-tailed taxa (e.g., Leptoceratops, Montanoceratops) which are known from fluvial deposits are inferred to be the poorest swimmers of the group. It should be noted that recently, Longrich (2010) argued that Protoceratops may have been nocturnal, and that its deep, narrow tail may have helped it to shed excess heat during the day when the animal was active, and to burrow into sand dunes to escape the heat during the day, thus explaining the specimens that have been recovered in an upright "standing" posture (Jerzykiewicz et al. 1993). Although the tail of Koreaceratops does not preclude it from having good swimming abilities, the evidence for such speculation is equivocal at this time. If the local paleoecology of the region from which the specimen was recovered can be determined in the future then further speculation about its lifestyle can be made.

Acknowledgments We thank J-H Kim for illustrations. Many thanks go also to Dr. Tereschenko for kindly providing their published papers to us. Two anonymous reviewers are thanked for the constructive comments on the original submission of this manuscript. The support and cooperation of Hwaseong City is gratefully acknowledged. This research was supported by Hwaseong City Cultural Foundation and the Basic Research Project (No. 10-3111) of the Korea Institute of Geoscience and Mineral Resources (KIGAM) funded by the Ministry of Knowledge Economy of Korea to the first author.

\section{References}

Averianov A, Sues H-D (2009) First record of a basal neoceratopsian dinosaur from the Late Cretaceous of Kazakhstan. Acta Palaeontol Pol 54:553-556

Bailey JB (1997) Neural spine elongation in dinosaurs: sail-backs or buffalo-backs? J Paleontol 71:1124-1146

Barsbold R (1974) Duelling dinosaurs. Priroda 2:81-83 (in Russian)

Brown B, Schlaikjer EM (1940) The structure and relationships of Protoceratops. Ann NY Acad Sci 40:133-266

Chinnery BJ (2004) Description of Prenoceratops pieganensis gen. et sp. nov. (Dinosauria: Neoceratopsia) from the Two Medicine Formation of Montana. J Vertebr Paleontol 24:572-590

Chinnery BJ, Horner JR (2007) A new neoceratopsian dinosaur linking North American and Asian taxa. J Vertebr Paleontol 27:625-641

Chinnery BJ, Weishampel DB (1998) Montanoceratops cerorhynchus (Dinosauria: Ceratopsia) and relationships among basal neoceratopsians. J Vertebr Paleontol 18:569-585

Chinnery-Allgeier BJ, Kirkland JI (2010) An update on the paleobiogeography of ceratopsian dinosaur. In: Ryan MJ, ChinneryAllgeier BJ, Eberth DA (eds) New perspectives on horned dinosaurs: The Royal Tyrrell Museum Ceratopsian Symposium. Indiana University Press, Bloomington, pp 387-404

Choe MY, Jo HR, Lee JI, Hur SD, Jeong KS (2001) Investigations on the geology and substrate remains in the abandoned tidal flats (Daebu Island area) of Sihwa Lake. Ansan City (in Korean).

Coombs WP Jr (1978) Theoretical aspects of cursorial adaptations in dinosaurs. Q Rev Biol 53:398-418

Dodson P, Farlow JO (1997) The forelimb carriage of ceratopsid dinosaurs. In: Wolberg DL, Stump E, Rosenberg GD (eds) 
Dinofest International. Academy of Natural Sciences, Philadelphia, pp 393-398

Dodson P, Forster CA, Sampson SD (2004) Ceratopsidae. In: Weishampel DB, Dodson P, Osmólska H (eds) The dinosauria, 2nd edn. University of California Press, Berkeley, pp 494-516

Dong Z-M, Azuma Y (1997) On a primitive neoceratopsian from the Early Cretaceous of China. In: Dong Z (ed) Sino-Japanese Silk Road Dinosaur Expedition. China Ocean Press, Beijing, pp 68-89

Eberth DA (1993) Depositional environments and facies transitions of dinosaur-bearing Upper Cretaceous redbeds at Bayan Mandahu (Inner Mongolia, People's Republic of China). Can J Earth Sci 30:2196-2213

Farke AA, Sampson SD, Forster CA, Loewen MA (2009) Turanoceratops tardabilis-sister taxon, but not a ceratopsid. Naturwissenschaften 96:869-870

Ford TL, Martin LD (2010) A semi-aquatic life habit for Psittacosaurus. In: Ryan MJ, Chinnery-Allgeier BJ, Eberth DA (eds) New perspectives on horned dinosaurs: The Royal Tyrrell Museum Ceratopsian Symposium. Indiana University Press, Bloomington, pp 327-339

Galton PM (1970) The posture of hadrosaurian dinosaurs. J Paleontol 44:464-473

Gregory WK, Mook CC (1925) On Protoceratops, a primitive ceratopsian dinosaur from the Lower Cretaceous of Mongolia. Am Mus Novit 156:1-9

Jerzykiewicz T, Currie PJ, Eberth DA, Johnston PA, Koster EH, Zheng JJ (1993) Djadokhta Formation correlative strata in Chinese Inner Mongolia: an overview of the stratigraphy, sedimentary geology, and paleontology and comparisons with the type locality in the preAltai Gobi. Can J Earth Sci 30:2180-2195

Kim SB, Kim Y-G, Jo HR, Jeong KS, Chough SK (2009) Depositional facies, architecture and environments of the Sihwa Formation (Lower Cretaceous), mid-west Korea with special reference to dinosaur eggs. Cretaceous Res 30:100-126

Kobayashi Y (2006) Dinosaurs from Japan. In: Lü J, Kobayashi Y, Dong H, Lee Y-N (eds) Papers from the 2005 Heyuan International Dinosaur Symposium. Geological Publishing House, Beijing, pp 87-102

Kurzanov SM (1992) Gigantskiy protoseratopsid iz verkhnengo mela Mongolii. Paleontol J 1992:81-93

Lambert O, Godefroit P, Li H, Shang C-Y, Dong Z-M (2001) A new species of Protoceratops (Dinosauria, Neoceratopsia) from the Late Cretaceous of Inner Mongolia (P. R. China). Bull Institut Roy Sci Natur Belg Sci Terre 71(Suppl):5-28.

Longrich N (2010) The function of large eyes in Protoceratops: a nocturnal ceratopsian? In: Ryan MJ, Chinnery-Allgeier BJ, Eberth DA (eds) New perspectives on horned dinosaurs: The Royal Tyrrell Museum Ceratopsian Symposium. Indiana University Press, Bloomington, pp 308-327

Lucas SG (2006) The Psittacosaurus biochron, Early Cretaceous of Asia. Cretaceous Res 27:189-198

Makovicky PJ (2001) A Montanoceratops cerorhynchus (Dinosauria: Ceratopsia) braincase from the Horseshoe Canyon Formation of Alberta. In: Tanke DH, Carpenter K (eds) Mesozoic vertebrate life: new research inspired by the paleontology of Philip J. Currie. Indiana University Press, Bloomington, pp 243-262

Makovicky PJ (2002) Taxonomic revision and phylogenetic relationships of basal Neoceratopsia (Dinosauria: Ornithischia). Dissertation, Columbia University

Makovicky PJ, Norell MA (2006) Yamaceratops dorngobiensis, a new primitive ceratopsian (Dinosauria: Ornithischia) from the Cretaceous of Mongolia. Am Mus Novit 3530:1-42

Makovicky PJ (2010) A redescription of the Montanoceratops cerorhynchus hototype with a review of referred material. In: Ryan MJ, Chinnery-Allgeier BJ, Eberth DA (eds) New perspectives on horned dinosaurs: The Royal Tyrrell Museum Ceratopsian Symposium. Indiana University Press, Bloomington, pp 68-82
Maryańska T, Osmólska H (1975) Protoceratopsidae (Dinosauria) of Asia. Palaeontol Pol 33:135-181

Nessov L, Kaznyshkina L, Cherepanov G (1989) Mesozoic dinosaurians - ceratopsians and crocodiles of Central Asia. Tr Sessii Vsesoyuznogo Paleontologicheskogo Obshch 33:144-154

Park S-D, Chung G-S, Jeong J-G, Kim W-S, Lee D-W, Song M-Y (2000) Structure and physical property of the crust of mid-west Korea: analysis of sedimentary basins in the Namyang and Tando areas, Kyeonggi Province, Korea. J Korean Earth Sci Soc 21:563-582 (in Korean with English abstract)

Park NY, Kim JH (1972) Geological map and explanatory text of Namyang area $(1: 50,000)$. Korea Institute of Geology Mining and Materials, Taejon (in Korean with English abstract)

Paul GS, Christiansen P (2000) Forelimb posture in neoceratopsian dinosaurs: implications for gait and locomotion. Paleobiology $26: 450-465$

Rega E, Holmes R, Tirabasso A (2010) Habitual locomotor behaviour inferred from manual pathology in two Late Cretaceous chasmosaurine ceratopsid dinosaurs, Chasmosaurus irvinensis (CMN 41357) and Chasmosaurus belli (ROM 843). In: Ryan MJ, Chinnery-Allgeier BJ, Eberth DA (eds) New perspectives on horned dinosaurs: The Royal Tyrrell Museum Ceratopsian Symposium. Indiana University Press, Bloomington, pp 340-354

Rozhdestvensky AK (1955) New data on Psittacosaurus-Cretaceous ornithopod. Quest Geol Asia 2:783-788

Ryan MJ (2009) The evolution of basal neoceratopsians and the origin of the Ceratopsidae. In: Lee Y-N (ed) Abstracts of 2009 Goseong International Dinosaur Symposium. Goseong County, Korea, pp 83-94

Ryan MJ, Currie PJ (1998) First report of protoceratopsians (Neoceratopsia) from the Late Cretaceous Judith River Group, Alberta, Canada. Can J Earth Sci 35:820-826

Senter P (2007) Analysis of forelimb function in basal ceratopsians. J Zool 273:305-314

Sereno PC (1986) Phylogeny of the bird-hipped dinosaurs (Order Ornithischia). Natl Geogr Res 2:234-256

Sereno PC (2000) The fossil record, systematics and evolution of pachycephalosaurs and ceratopsians from Asia. In: Benton MJ, Shishkin MA, Unwin DM, Kurochkin EN (eds) The Age of dinosaurs in Russia and Mongolia. Cambridge University Press, New York, pp 480-516

Sereno PC (2010) Taxonomy, cranial morphology, and relationships of parrot-beaked dinosaurs (Ceratopsia: Psittacosaurus). In: Ryan MJ, Chinnery-Allgeier BJ, Eberth DA (eds) New perspectives on horned dinosaurs: The Royal Tyrrell Museum Ceratopsian Symposium. Indiana University Press, Bloomington, pp 21-58

Sternberg CM (1951) Complete skeleton of Leptoceratops gracilis Brown from the Upper Edmonton member on the Red Deer River, Alberta. Bull Nat Mus Can 123:225-255

Sues H-D, Averianov A (2009a) Turanoceratops tardabilis-the first ceratopsid dinosaur from Asia. Naturwissenschaften 96:645652

Sues H-D, Averianov A (2009b) Phylogenetic position of Turanoceratops (Dinosauria: Ceratopsia). Naturwissenschaften 96:871-872

Suslov JV (1983) The locality of Psittacosaurus in Khamrin-us (East Gobi, MPR). Trans Jt Sov Mong Paleontol Exped 24:118-121

Swofford DL (1998) PAUP*, phylogenetic analysis using parsimony (*and other methods). Version 4B10. Sinauer Associates, Sunderland, Massachusetts.

Tereschenko VS (2008) Adaptive features of protoceratopoids (Ornithischia: Neoceratopsia). Paleontol J 42:273-286

Thompson S, Holmes R (2007) Forelimb stance and step cycle in Chasmosaurus irvinensis (Dinosauria: Neoceratopsia). Palaeontol Electron 10:5A:17p.

Xu X, Forster CA, Clark JM, Mo J (2006) A basal ceratopsian with transitional features from the Late Jurassic of northwestern China. Proc R Soc Lond Ser B 273:2135-2140 
Xu X, Wang K, Zhao X, Li D (2010) First ceratopsid dinosaur from China and its biogeographic implications. Chinese Sci Bull 55:1631-1635

Yi S, Lee Y-N, Lee S-J (2004) Palynofacies of the Cretaceous sediments in the Tando Basin, west Korea: thermal maturation and its geological implication. J Geol Soc Korea 40:431-439 (in Korean with English abstract)

You H, Dodson P (2003) Redescription of neoceratopsian dinosaur Archaeoceratops and early evolution of Neoceratopsia. Acta Paleontol Pol 48:261-272

You H, Dodson P (2004) Basal Ceratopsia. In: Weishampel DB, Dodson P, Osmólska H (eds) The dinosauria, 2nd edn. University of California Press, Berkeley, pp 478-493
Wolfe DG, Kirkland JI (1998) Zuniceratops christopheri n. gen. \& n. sp., a ceratopsian dinosaur from the Moreno Hill Formation (Cretaceous, Turonian) of West-Central New Mexico. In: Lucas SG, Kirkland JI, Estep JW (eds) Lower and Middle Cretaceous terrestrial ecosystems. New Mexico Museum of Natural History and Sci Bull 14:303-317

Wolfe DG, Kirkland JI, Smith D, Poole K, Chinnery-Allgeier BJ, McDonald A (2010) Zuniceratops christopheri: the North American ceratopsid sister taxon reconstructed on the basis of new data. In: Ryan MJ, Chinnery-Allgeier BJ, Eberth DA (eds) New perspectives on horned dinosaurs: The Royal Tyrrell Museum Ceratopsian Symposium. Indiana University Press, Bloomington, pp 91-98 